\title{
Esterification of Microwave Pyrolytic Oil from Palm Oil Kernel Shell
}

\author{
Sharifah Mona Abdul Aziz, ${ }^{1}$ Rafeah Wahi, ${ }^{2}$ Zainab Ngaini, ${ }^{2}$ \\ Sinin Hamdan, ${ }^{3}$ and Syamila Aimi Yahaya ${ }^{2}$ \\ ${ }^{1}$ Centre of Pre-University Studies, Universiti Malaysia Sarawak, 94300 Kota Samarahan, Sarawak, Malaysia \\ ${ }^{2}$ Department of Chemistry, Faculty of Resource Science and Technology, Universiti Malaysia Sarawak, \\ 94300 Kota Samarahan, Sarawak, Malaysia \\ ${ }^{3}$ Department of Mechanical and Manufacturing Engineering, Faculty of Engineering, Universiti Malaysia Sarawak, \\ 94300 Kota Samarahan, Sarawak, Malaysia
}

Correspondence should be addressed to Rafeah Wahi; wrafeah@unimas.my

Received 2 December 2016; Revised 15 February 2017; Accepted 22 February 2017; Published 13 March 2017

Academic Editor: Hakan Arslan

Copyright (C) 2017 Sharifah Mona Abdul Aziz et al. This is an open access article distributed under the Creative Commons Attribution License, which permits unrestricted use, distribution, and reproduction in any medium, provided the original work is properly cited.

\begin{abstract}
Microwave pyrolysis is a potential for producing alternative fuel from biomass, such as palm kernel shell (PKS). However, the resulting microwave pyrolytic oil (bio-oil) was highly acidic and has low calorific value and therefore must undergo additional process to improve the physicochemical properties. In this study, attempt was made to improve the $\mathrm{pH}$ and calorific value of bio-oil produced from PKS via esterification process. The effect of esterification with ethanol in the presence of sulphuric acid as a catalyst on selected biodiesel qualities was also investigated. The esterification process has successfully improved the $\mathrm{pH}$ value from 3.37 to 5.09-5.12 and the calorific value was increased from 27.19 to $34.78-41.52 \mathrm{MJ} / \mathrm{kg}$. Conclusively, the EO has comparatively better properties in terms of its smell, $\mathrm{pH}$, calorific value, and absence of environmentally undesirable compounds. However, future works should include ASTM 6751 specifications tests for biodiesel to evaluate the bio-oil's suitability for commercial use.
\end{abstract}

\section{Introduction}

Palm kernel shell (PKS) is a highly abundant waste generated from palm oil industry with high volatile matter content. PKS can be converted into renewable energy sources when subjected to suitable treatment such as microwave pyrolysis. In pyrolysis process, the biomass undergoes thermal decomposition in an oxygen-free environment to produce liquid, carbon-rich solid residue, and gases fuels synchronously.

In traditional pyrolysis, the system was performed using fixed bed, fluidized bed, circulating fluidized bed, and powder-particle fluidized bed, in which samples are heated externally using electrical heating [1]. Conventional heating has certain limitations such as heat transfer resistance, heat losses to surrounding, utilization of portion of heat supplied to biomass materials, and damage to reactor walls due to continuous electric heating [2]. Moreover, long heating period causes negative reactions in an undesirable or secondary reaction.

In the past decade, pyrolysis of biomass under microwave radiation has gained a lot of attention due to its advantages. During microwave pyrolysis, the microwave energy is accumulated precisely inside the material which creates spontaneous heat [3]. Microwave heating has been practiced to numerous kinds of biomass pyrolysis such as coal [4], oil shales [5], plastic wastes [6], sewage sludge [7, 8], wood block [9], corn stover [10], coffee hulls [11], rice straw [3], and pine sawdust [12].

In conventional heating, the heat is transported into the material through transmission, conduction, and radiation of heat from the surface of the material. In contrast, microwave energy is distributed straight into materials through molecular synergy with the electromagnetic field, thus obtaining a more uniform circulation of heat correlated with conventional heating $[3,10]$. Uniform circulation of heat 
TABLE 1: Parameter for esterification.

\begin{tabular}{lcccc}
\hline Sample & Ethanol-to-oil ratio (wt\% of oil) & Reaction temperature $\left({ }^{\circ} \mathrm{C}\right)$ & Reaction time $(\mathrm{min})$ & Catalyst $(\mathrm{wt} \%$ of oil) \\
\hline EO1 & $1: 1$ & 65 & 120 & 120 \\
EO2 & $2: 1$ & 65 & 120 & 2 \\
EO3 & $3: 1$ & 65 & 60 & 2 \\
EO4 & $1: 1$ & 70 & 60 & 2 \\
EO5 & $2: 1$ & 70 & 60 & 2 \\
EO6 & $3: 1$ & 70 & & 2 \\
\hline
\end{tabular}

enables a well-controlled temperature adjustment and hence improved the process and the desired end products [10]. In addition, microwave heating contributes to volumetric heating mechanism at enhanced heating capability which saves energy compared to conventional systems [13].

In the sense of bio-oil production, microwave pyrolysis has been reported to prevent the chemical changes of volatiles product, thus attributed to better yield of bio-oil with low polycyclic aromatic hydrocarbons (PAHs) examined with those bio-oil obtained from conventional electrical furnace [7]. A study on microwave pyrolysis of rice straw also reported that the bio-oil product was highly alkylated and oxygenated and has less hazardous PAHs content [3]. However, significant concentrations of PAHs in bio-oil were reported when the input power of microwave was increased from 300 to $900 \mathrm{~W}$ [10].

Similar to other studies, microwave bio-oil has undesirable characteristics such as exalted viscosity, deficient heating rate, corrosiveness, and low resistance [14]. These properties will cause problems for direct use by engines. The microwave bio-oil is also highly acidic and has low calorific value and therefore must undergo additional process to improve the physicochemical properties. Esterification is a potential route to convert carboxylic acid in the bio-oil into ester by reacting them with alcohol, to improve the viscosity, corrosivity, calorific value, and chemical stability of the bio-oil as a fuel [14-16]. Thus, in this study, attempt was made to improve the $\mathrm{pH}$ and calorific value of bio-oil produced from PKS via esterification process.

\section{Experimental}

\subsection{Materials}

2.2. Experimental Setup. The experiments were carried out by setting samples in a quartz reactor and putting them inside the microwave. The quartz reactor was constructed using $15 \mathrm{~mm}$ inner diameter of gas inlet and outlet. Nitrogen gas was used to create an inert atmosphere in the reactor. A flow rate meter was used to control the gas purging into the reactor. The gas outlet was fastened to a condenser with tap water as a cooling condition.

2.3. Esterification of Bio-Oil. The esterification was performed by reacting PKO $(1 \mathrm{~g})$ with ethanol in the presence of sulphuric acid (as a catalyst). The esterification parameters are shown in Table 1. The molar ratio of ethanol to biooil was $1: 1,2: 1$, and $3: 1$ in 2 wt\% of homogeneous catalyst. The mixture was refluxed for 60 and 120 minutes. A molecular sieve was used as a desiccant to remove water of reaction. The mixture was poured into a separating funnel containing $20 \mathrm{~mL}$ water. The flask was rinsed with diethyl ether $(20 \mathrm{~mL})$ and transferred into the separating funnel. The water layer was drained off and the ether layer was washed with water $(20 \mathrm{~mL})$ and $5 \%$ sodium bicarbonate. Saturated sodium chloride solution was added to the ether layer and freed from moisture by using anhydrous sodium sulphate and concentrated using a rotary evaporator. The esterified bio-oil (EO) was characterized using GC-MS. The EO was further characterized for its physical properties.

The CV of EO was analysed. The $\mathrm{pH}$ of the $\mathrm{EO}$ was measured using a $\mathrm{pH}$ meter from Eutech Instrument, type of pH 5/10. The EO density was determined using measuring cylinder and analytical balance. The EO was also analysed using FTIR spectrometer (Model: PerkinElmer Spectrum GX) and GC-MS (Model: Shimadzu-GCMS QP2010 Plus). A capillary column BPX-5 $(29.5 \mathrm{~m} \times 0.25 \mathrm{~mm}$ id., $0.25 \mu \mathrm{m}$ thick film thickness) was used. The initial temperature of $40^{\circ} \mathrm{C}$ was held for $5 \mathrm{~min}$. The temperature was programmed at 40 to $300^{\circ} \mathrm{C}$ at $5^{\circ} \mathrm{C} / \mathrm{min}$ and followed by isothermal conditions for $30 \mathrm{~min}$. The split ratio was $20: 1$ and the injection temperature was at $300^{\circ} \mathrm{C}$. The injection size was $1 \mu \mathrm{L}$ and the flow rate of carrier gas (Helium) was $1.5 \mathrm{~mL} / \mathrm{min}$. The ion source and transfer line temperatures were $290^{\circ} \mathrm{C}$ correspondingly. Data were collected in the full-scan mode from $\mathrm{m} / \mathrm{z} 28$ to 500 with a solvent delay of $2 \mathrm{~min}$. The compounds were determined by comparison with the mass spectra available in the NIST library in MS database.

\section{Results and Discussion}

3.1. Esterification of Bio-Oil. The chemical compositions of the PKO (Figure 1) and the EO at several parameters EO1, EO2, EO3, EO4, EO5, and EO6 (Figures 2(a)-2(f)) were characterized using GC-MS. In comparison to Figure 1, significant peaks at retention time, $R_{t}=30.2$, 34.7, 38.7, 41.9, and $42.3 \mathrm{~min}$, were observed in the EO, which did not appear in PKO. These peaks were attributed to the formation of lauric acid ethyl ester, myristic acid ethyl ester, palmitic acid ethyl ester, oleic acid ethyl ester, and stearic acid ethyl ester, respectively [15]. The peak at $R_{t}=12.9 \mathrm{~min}$ which represents phenol was observed to remain in the EO. The peaks of 


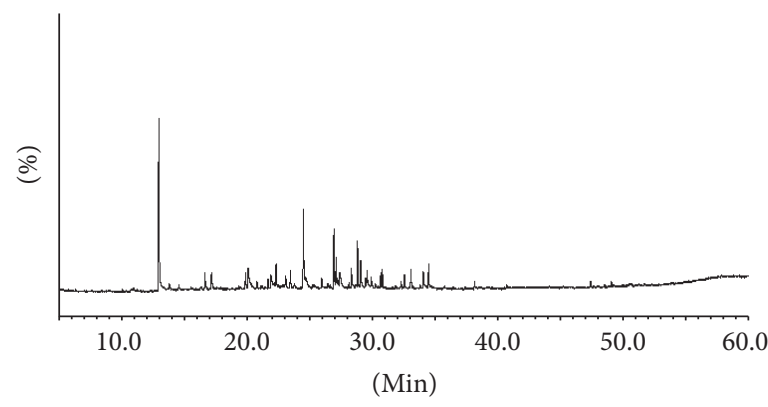

FIGURE 1: Gas chromatogram of PKO.

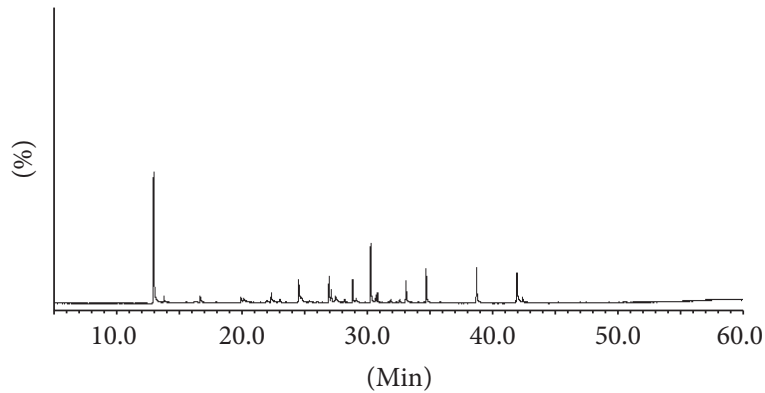

(a) EO1

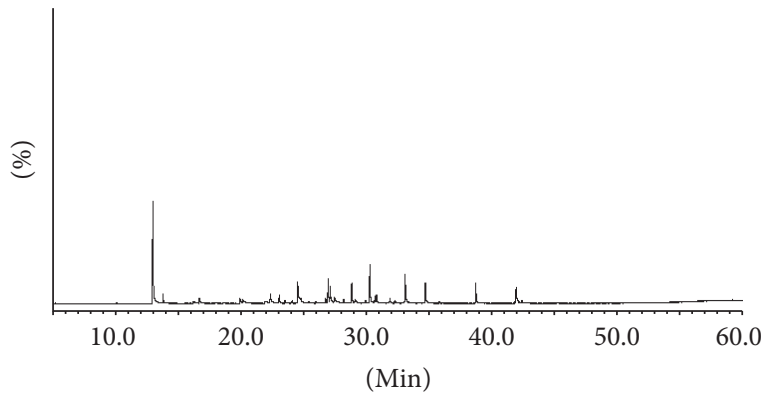

(c) $\mathrm{EO} 3$

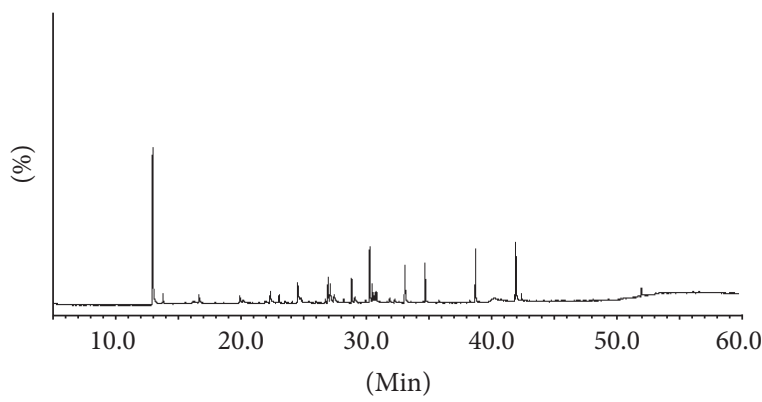

(e) $\mathrm{EO} 5$

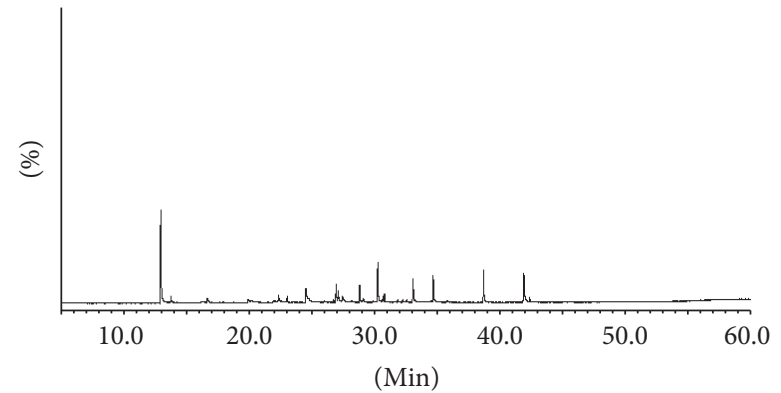

(b) $\mathrm{EO} 2$

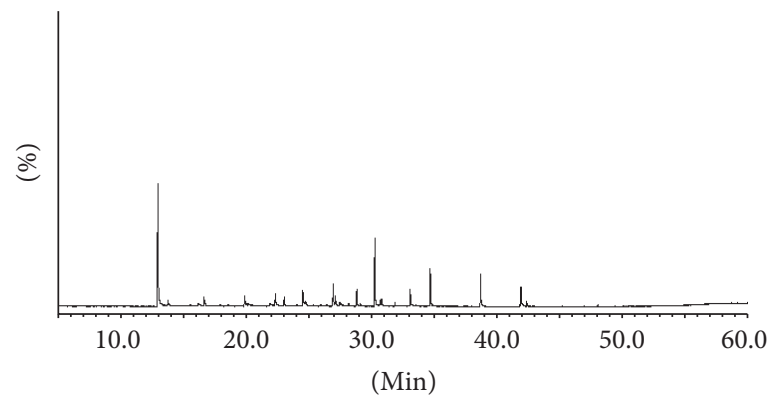

(d) $\mathrm{EO} 4$

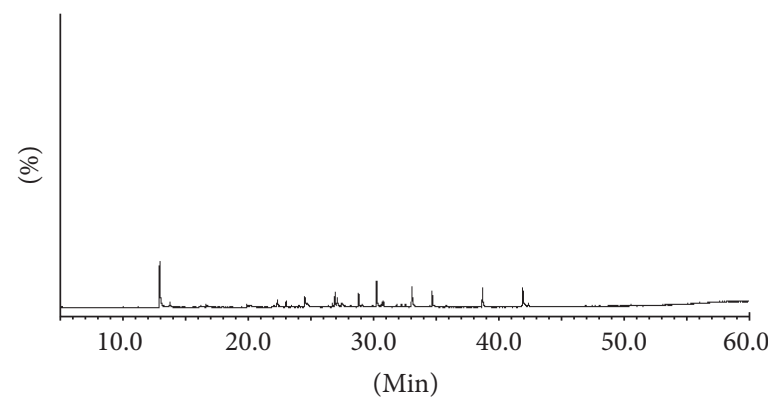

(f) EO6

FIGURE 2: Gas chromatograms of EO.

carboxylic acid such as lauric acid and myristic acid at $R_{t}=$ 29.5 and $34.0 \mathrm{~min}$ were not observed in the EO, indicating the conversion of carboxylic acids into ester. The peaks at $R_{t}=17.1$ and $28.3 \mathrm{~min}$ in $\mathrm{PKO}$ which represent pentanal and levoglucosan, respectively, were not observed in the EO. Meanwhile, other aldehyde and ketone groups in PKO remained in the $\mathrm{EO}$ at low proportions.
The percentage area (\%) of EO was analysed for the relative contents of the compounds present in the EO at the same concentration. The main components of compounds present in the $\mathrm{EO}$ at different parameters and the comparison between $\mathrm{EO}$ concentrated at $35^{\circ} \mathrm{C}$ and $78^{\circ} \mathrm{C}$ are shown in Table 2. The total percentage area (\%) of the desirable ester compounds was higher in the EO than in the PKO, which 
TABLE 2: Chemical composition of PKO and EO (not marked: concentrated at $35^{\circ} \mathrm{C}$; marked (*): concentrated at $78^{\circ} \mathrm{C}$ ).

\begin{tabular}{|c|c|c|c|c|c|c|c|}
\hline \multirow{2}{*}{ Compound Name } & \multicolumn{7}{|c|}{ Percentage area $(\%)$} \\
\hline & $\mathrm{PKO}$ & EO1 & $\mathrm{EO} 2$ & EO3 & EO4 & EO5 & EO6 \\
\hline \multicolumn{8}{|c|}{ Monoaromatic compounds } \\
\hline \multirow{2}{*}{ Phenol } & \multirow{2}{*}{26.15} & 26.34 & 24.87 & 24.65 & 28.18 & 24.44 & 20.64 \\
\hline & & $20.20^{*}$ & $20.07^{*}$ & $22.96^{*}$ & $25.18^{*}$ & $21.00^{*}$ & $18.25^{*}$ \\
\hline \multirow{2}{*}{ 2-Methoxy-phenol } & \multirow{2}{*}{2.36} & 1.77 & 1.48 & 1.97 & 2.14 & 1.36 & - \\
\hline & & $1.62^{*}$ & $1.75^{*}$ & $1.35^{*}$ & $2.11^{*}$ & $1.66^{*}$ & $1.21^{*}$ \\
\hline \multirow{2}{*}{ 2-Methoxy-4-methyl-phenol } & \multirow{2}{*}{2.38} & 1.46 & 1.32 & 1.45 & 2.77 & 1.56 & 0.94 \\
\hline & & $1.96^{*}$ & $1.99^{*}$ & $1.71^{*}$ & $2.74^{*}$ & $2.18^{*}$ & $1.87^{*}$ \\
\hline 1,2-Benzenediol & 3.78 & - & - & - & - & - & - \\
\hline \multirow{2}{*}{ 3-Methoxy-1,2-benzenediol } & \multirow{2}{*}{1.1} & - & - & - & - & - & - \\
\hline & & $0.98^{*}$ & - & - & - & - & - \\
\hline 4-Methyl-1,2-benzenediol & - & 0.47 & - & - & - & - & - \\
\hline \multirow{2}{*}{ 4-Ethyl-2-methoxyphenol } & \multirow{2}{*}{2.21} & 2.11 & 1.52 & 2.46 & 2.65 & 2.07 & 2.20 \\
\hline & & $2.74^{*}$ & $2.97^{*}$ & $2.55^{*}$ & $3.14^{*}$ & $3.15^{*}$ & $3.07^{*}$ \\
\hline \multirow{2}{*}{ 2-Methoxy-4-vinylphenol } & \multirow{2}{*}{2.11} & - & - & 0.41 & - & 0.27 & - \\
\hline & & - & - & - & - & - & $0.58^{*}$ \\
\hline \multirow{2}{*}{ 2,6-Dimethoxyphenol } & \multirow{2}{*}{11.14} & 7.39 & 6.29 & 7.68 & 4.98 & 5.61 & 6.53 \\
\hline & & $7.4^{*}$ & $7.04^{*}$ & $7.64^{*}$ & $5.52^{*}$ & $7.88^{*}$ & $7.31^{*}$ \\
\hline 3,4-Dimethoxyphenol & - & - & - & 0.8 & - & - & - \\
\hline \multirow{2}{*}{ 2-Methoxy-4-propylphenol } & \multirow{2}{*}{-} & 1.08 & 1.5 & 1.26 & 1.43 & 0.94 & 1.49 \\
\hline & & $1.27^{*}$ & $0.92^{*}$ & $0.93^{*}$ & $1.18^{*}$ & $1.51^{*}$ & $1.16^{*}$ \\
\hline 2-Methoxy-4-(1-propenyl)-phenol & - & 0.14 & - & - & - & - & - \\
\hline \multirow{2}{*}{ 1,2,4-Trimethoxybenzene } & 7.21 & 5.37 & 4.86 & 5.65 & 4.90 & 3.74 & 5.48 \\
\hline & 1.21 & $5.68^{*}$ & $5.54^{*}$ & $6.3^{*}$ & $5.20^{*}$ & $6.10^{*}$ & $5.88^{*}$ \\
\hline 2-Methoxy-4-(1-propenyl)phenol & 4.23 & 2.82 & 2.83 & 3.81 & 2.43 & 3.46 & 3.81 \\
\hline 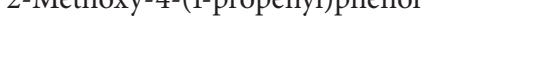 & 4.25 & $3.33^{*}$ & $3.73^{*}$ & $4.1^{*}$ & $2.69^{*}$ & $4.40^{*}$ & $4.08^{*}$ \\
\hline 2,6-Bis(1,1-dimethylethyl)-4-methylphenol & - & 0.23 & 0.49 & 0.71 & 0.41 & 0.53 & 0.26 \\
\hline 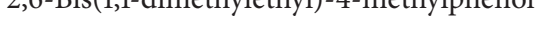 & - & $0.6^{*}$ & $0.63^{*}$ & $0.62^{*}$ & $0.61^{*}$ & $0.33^{*}$ & - \\
\hline 1,2,3-Trimethoxy-5-methylbenzene & 4.25 & 4.11 & 3.9 & 4.37 & 3.46 & 3.54 & 4.73 \\
\hline 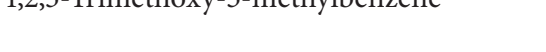 & 4.25 & $4.52^{*}$ & $4.2^{*}$ & $4.58^{*}$ & $3.55^{*}$ & $4.86^{*}$ & $4.56^{*}$ \\
\hline 2,6-Dimethoxy-4-(2-propenyl)phenol & 1.26 & 1.29 & 1.29 & 1.24 & 1.08 & 1.67 & 1.21 \\
\hline 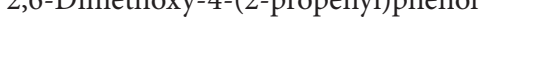 & 1.20 & $1.33^{*}$ & $1.22^{*}$ & $1.3^{*}$ & $1.27^{*}$ & $1.58^{*}$ & $1.43^{*}$ \\
\hline 2,6-Dimethoxy-4-(2-propenyl)phenol & - & 0.49 & 0.46 & 0.86 & 0.61 & 0.73 & 0.63 \\
\hline 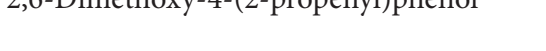 & - & $0.84^{*}$ & $0.86^{*}$ & $0.91^{*}$ & $0.83^{*}$ & $0.97^{*}$ & $1.01^{*}$ \\
\hline 2,6-Dimethoxy-4-(2-propenyl)phenol & 4.34 & 4.59 & 6.46 & 7.97 & 3.89 & 6.04 & 8.18 \\
\hline 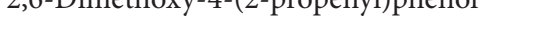 & 4.54 & $3.08^{*}$ & $3.99^{*}$ & $6.28^{*}$ & $4.30^{*}$ & $4.97^{*}$ & $6.39^{*}$ \\
\hline Total & 72.52 & 59.66 & 57.27 & 65.29 & 58.93 & 55.96 & 56.1 \\
\hline Tolal & 2.32 & $55.55^{*}$ & $54.91^{*}$ & $61.23^{*}$ & $58.56^{*}$ & $60.59^{*}$ & $56.80^{*}$ \\
\hline & & Carbox & & & & & \\
\hline Dodecanoic acid & 1.64 & - & - & - & - & - & - \\
\hline 3,4,5-Trimethoxyphenylacetic acid & - & - & 0.41 & 0.52 & - & 0.34 & 0.68 \\
\hline 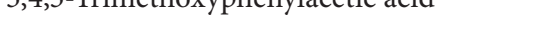 & - & - & $0.65^{*}$ & $0.91^{*}$ & - & $0.54^{*}$ & $0.76^{*}$ \\
\hline Tetradecanoic acid & 2.3 & - & - & - & - & - & - \\
\hline 9,12-Octadecadienoic acid & - & 0.35 & - & - & - & - & - \\
\hline & - & $0.66^{*}$ & $0.62^{*}$ & - & - & - & - \\
\hline Total & 3.94 & 0.35 & 0.41 & 0.52 & - & 0.34 & 0.68 \\
\hline & 0.94 & $0.66^{*}$ & $1.27^{*}$ & $0.91^{*}$ & - & $0.54^{*}$ & $0.76^{*}$ \\
\hline & & & & & & & \\
\hline 2-Pentanone & 0.93 & - & - & 一 & - & - & - \\
\hline
\end{tabular}


TABLE 2: Continued.

\begin{tabular}{|c|c|c|c|c|c|c|c|}
\hline \multirow{2}{*}{ Compound Name } & \multicolumn{7}{|c|}{ Percentage area (\%) } \\
\hline & $\mathrm{PKO}$ & EO1 & $\mathrm{EO} 2$ & EO3 & EO4 & $\mathrm{EO} 5$ & EO6 \\
\hline \multirow{2}{*}{ 1-(4-Hydroxy-3,5-dimethoxyphenyl)ethanone } & \multirow{2}{*}{-} & - & - & - & - & - & 1.22 \\
\hline & & - & - & - & - & - & $1.08^{*}$ \\
\hline \multirow{2}{*}{ 1-(4-Hydroxy-3-methoxyphenyl)-2-propanone } & \multirow{2}{*}{3.16} & 0.49 & 0.82 & 0.79 & - & 1.02 & 0.79 \\
\hline & & $1.51^{*}$ & $1.00^{*}$ & - & $0.36^{*}$ & $0.87^{*}$ & $1.40^{*}$ \\
\hline \multirow{2}{*}{ (3,5-Dimethoxyphenyl)-ethanone } & \multirow{2}{*}{1.38} & - & - & 0.43 & - & 0.40 & 0.35 \\
\hline & & - & - & $0.47^{*}$ & - & $0.45^{*}$ & $0.51^{*}$ \\
\hline \multirow{2}{*}{ 1-(2,6-Dihydroxy-4-methoxyphenyl)-1-butanone } & \multirow{2}{*}{-} & - & 0.33 & - & - & - & 0.24 \\
\hline & & $0.9^{*}$ & $0.75^{*}$ & $0.76^{*}$ & $0.23^{*}$ & $1.30^{*}$ & $0.98^{*}$ \\
\hline \multirow{2}{*}{ Total } & \multirow{2}{*}{5.47} & 0.49 & 1.15 & 1.22 & - & 1.42 & 2.6 \\
\hline & & $2.41^{*}$ & $1.75^{*}$ & $1.23^{*}$ & $0.59^{*}$ & $2.62^{*}$ & $3.97^{*}$ \\
\hline \multicolumn{8}{|c|}{ Aldehydes } \\
\hline Pentanal & 2.59 & - & - & - & - & - & - \\
\hline 4-Hydroxy-3-methoxybenzaldehyde & 1.08 & - & - & - & - & - & - \\
\hline 2-Diethoxymethyl-3-methyl-butyraldehyde & - & - & - & - & - & $0.33^{*}$ & - \\
\hline \multirow{2}{*}{ 3,4,5-Trimethoxy-benzaldehyde } & \multirow{2}{*}{-} & - & 0.65 & 1.01 & - & 0.51 & - \\
\hline & & - & - & $1.14^{*}$ & - & $0.75^{*}$ & - \\
\hline \multirow{2}{*}{ Total } & \multirow{2}{*}{3.67} & - & 0.65 & 1.01 & - & 0.51 & - \\
\hline & & - & - & $1.14^{*}$ & - & $1.08^{*}$ & - \\
\hline \multicolumn{8}{|c|}{ Esters } \\
\hline Acetic acid, diethox, ethylester & - & - & - & - & $0.23^{*}$ & $0.19^{*}$ & - \\
\hline \multirow{2}{*}{ Benzoic acid, 4-hydroxy-, methyl ester } & \multirow{2}{*}{1.52} & 1.68 & 1.88 & 1.54 & 0.65 & 1.23 & 1.51 \\
\hline & & $2.23^{*}$ & $2.09^{*}$ & $1.38^{*}$ & $1.06^{*}$ & $1.92^{*}$ & $2.12^{*}$ \\
\hline Dodecanoic acid, ethyl ester & - & 10.47 & 9.23 & 8.56 & 13.12 & 8.16 & 9.29 \\
\hline & & $9.88^{*}$ & $9.38^{*}$ & $8.64^{*}$ & $11.46^{*}$ & $8.06^{*}$ & $8.40^{*}$ \\
\hline 1,2-Benzenedicarboxylic acid, diethyl ester & - & - & - & - & - & 3.65 & - \\
\hline 2,4-Hexadienedioic acid, 3,4-diethyl- dimethyl ester & 1.66 & 1.68 & 1.65 & 1.76 & 1.48 & 1.62 & 1.79 \\
\hline & & $1.61^{*}$ & $1.74^{*}$ & $1.68^{*}$ & $1.62^{*}$ & $1.99^{*}$ & $1.76^{*}$ \\
\hline 2-Propenoic acid, tridecyl ester & 1.1 & - & 0.43 & - & - & - & - \\
\hline Tetradecanoic acid ethyl ester & - & 6.44 & 6.37 & 4.98 & 8.00 & 5.16 & 5.51 \\
\hline Tetracecanor acid, etmyr ester & - & $6.67^{*}$ & $6.11^{*}$ & $5.27^{*}$ & $7.58^{*}$ & $5.45^{*}$ & $5.85^{*}$ \\
\hline Hexadecanoic acid ethyl ester & - & 7.24 & 7.79 & 5.44 & 7.08 & 7.08 & 7.22 \\
\hline 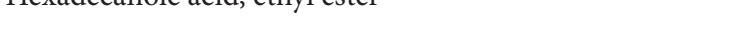 & & $8.42^{*}$ & $7.88^{*}$ & $6.76^{*}$ & $8.08^{*}$ & $6.80^{*}$ & $7.06^{*}$ \\
\hline 9,12-Octadecadienoic acid (Z,Z)-, ethyl ester & - & - & - & - & 0.27 & 0.75 & 0.56 \\
\hline & & - & - & - & $0.61^{*}$ & - & - \\
\hline 9,12-Octadecadienoic acid (Z,Z)-, methyl ester & - & - & 0.41 & - & - & - & - \\
\hline & & - & - & - & - & $0.56^{*}$ & $0.71^{*}$ \\
\hline 9-Octadecenoic acid (Z)-, ethyl ester & - & 8.97 & 8.88 & 4.7 & 5.06 & 9.67 & 9.72 \\
\hline 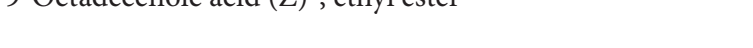 & - & $9.35^{*}$ & $9.59^{*}$ & $6.58^{*}$ & $6.22^{*}$ & $7.35^{*}$ & $8.42^{*}$ \\
\hline Octadecanoic acid, ethyl ester & - & 1.06 & 0.97 & 0.55 & 0.97 & 1.07 & 1.16 \\
\hline 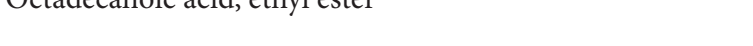 & & $1.14^{*}$ & $1.07^{*}$ & $0.87^{*}$ & $1.22^{*}$ & $0.89^{*}$ & $1.03^{*}$ \\
\hline 1,2-Benzenedicarboxylic acid, diisooctyl ester & - & - & - & - & 0.34 & - & - \\
\hline Total & 4.28 & 37.54 & 37.61 & 27.53 & 36.97 & 38.39 & 36.76 \\
\hline & 4.20 & $39.30^{*}$ & $37.86^{*}$ & $31.18^{*}$ & $38.08^{*}$ & $33.21^{*}$ & $35.35^{*}$ \\
\hline & Anhydr & ars & & & & & \\
\hline Methyl 4-O-acetyl-2,3,6-tri-O-ethyl- $\alpha$-d-galactopyranoside & - & 0.38 & 1.12 & 1.53 & 1.57 & 1.08 & 1.43 \\
\hline 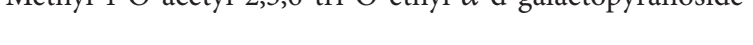 & & $0.37^{*}$ & $1.24^{*}$ & $1.44^{*}$ & $1.21^{*}$ & $1.05^{*}$ & $1.20^{*}$ \\
\hline 1,3-Di-O-acetyl-.alpha.-.beta.-d-ribopyranose & 0.83 & - & - & - & - & - & - \\
\hline$\beta$-D-Glucopyranose,1,6-anhydro-(Levoglucosan) & 1.44 & - & - & - & - & - & - \\
\hline$\beta$-D-Glucopyranose,1,6-anhydro-(Levoglucosan) & 3.15 & - & - & - & - & - & - \\
\hline
\end{tabular}


TABLE 2: Continued.

\begin{tabular}{|c|c|c|c|c|c|c|c|}
\hline \multirow{2}{*}{ Compound Name } & \multicolumn{7}{|c|}{ Percentage area $(\%)$} \\
\hline & $\mathrm{PKO}$ & EO1 & $\mathrm{EO} 2$ & $\mathrm{EO} 3$ & $\mathrm{EO} 4$ & EO5 & EO6 \\
\hline 1,3-Di-O-acetyl-.alpha.-.beta.-d-ribopyranose & 0.95 & - & - & - & - & - & - \\
\hline \multirow{2}{*}{ Total } & \multirow{2}{*}{6.37} & 0.38 & 1.12 & 1.53 & 1.57 & 1.08 & 1.43 \\
\hline & & $0.37^{*}$ & $1.24^{*}$ & $1.44^{*}$ & $1.21^{*}$ & $1.05^{*}$ & $1.20^{*}$ \\
\hline \multicolumn{8}{|c|}{ Nitrogenated compound } \\
\hline $\mathrm{N}$-Butyl-tert-butylamine & 1.2 & - & - & - & - & - & - \\
\hline \multicolumn{8}{|c|}{ Other compounds } \\
\hline & \multirow{2}{*}{0.72} & 1.61 & 1.79 & 2.90 & 2.54 & 2.33 & 2.42 \\
\hline & & $1.72^{*}$ & $2.98^{*}$ & $2.88^{*}$ & $1.55^{*}$ & $0.92^{*}$ & $1.91^{*}$ \\
\hline
\end{tabular}

TABLE 3: Comparison of PKO and EO after esterification.

\begin{tabular}{lcccc}
\hline Properties & PKO & EO (concentrated at $\left.35^{\circ} \mathrm{C}\right)$ & EO (concentrated at $\left.78^{\circ} \mathrm{C}\right)$ & Commercial diesel $($ Khor et al., 2009a) \\
\hline Color & Dark brown & Dark brown & Dark brown & Light yellow \\
Odour & Acrid smoky & Pleasant smell & Pleasant smell & Strong odour \\
$\mathrm{pH}$ & 3.37 & 5.09 & 5.12 & Neutral \\
Density $\left(\mathrm{g} / \mathrm{cm}^{3}\right)$ & 1.07 & 0.94 & 0.95 & 0.85 \\
Calorific value $(\mathrm{MJ} / \mathrm{kg})$ & 27.19 & 34.78 & 41.52 & 45.80 \\
\hline
\end{tabular}

indicated the successful esterification of PKO. Doshi et al. [15] reported on the esterification of low molecular fatty acid (acetic acid and propanoic acid) and high molecular fatty acid in sewage sludge bio-oil. In comparison to Doshi et al. [15] study, it was observed that high molecular fatty acid of this bio-oil has been converted to its corresponding ester such as lauric acid ethyl ester, myristic acid ethyl ester, palmitic acid ethyl ester, and oleic acid ethyl ester. The low molecular fatty acid in esterification was not observed possibly due to a small fraction of the volatile acid in the bio-oil. This indicated that the ester compounds observed after the esterification were dependent on the organic acid in the bio-oil [16].

The undesirable compounds that are mainly responsible for the ageing reactions, instability, and corrosiveness such as aldehyde, ketones, and carboxylic acid were reduced in the EO. The anhydrosugar compound such as levoglucosan was also not observed in the EO. This is attributed from the extraction of EO using diethyl ether to separate the water soluble components in the EO [17]. Meanwhile, the phenol and phenolic compounds remained in the EO which displays inactive reactivity during catalytic esterification [18].

Increasing the ratio of ethanol to oil at $3: 1$ gave a decreasing trend of percentage area (\%) of ester. The decreasing trend of percentage area (\%) of ester might be due to water, a by-product obtained during esterification. Water is a major interference to acid catalyst esterification which obstructs the conversion of acids into ester to be completed [15, 18]. Water could inhibit the catalytic activity through deactivation of the sulphuric acid catalyst by the loss in acid durability of catalytic protons [19]. The use of molecular sieve $4 \mathrm{~A}$ did not efficiently absorb water during esterification.

The unreacted ethanol was usually found in EO unless complete esterification has been achieved [15]. Therefore, $\mathrm{EO}$ was concentrated at $78^{\circ} \mathrm{C}$ using rotary evaporator in order to remove the unreacted ethanol and to investigate the difference in composition of EO as well as its properties. The EO which was concentrated at $78^{\circ} \mathrm{C}$ gave relatively similar composition with EO that was being concentrated at $35^{\circ} \mathrm{C}$ with relatively small changes in the percentage area (\%) of some compounds.

The IR spectra of the PKO and the EO are shown in Figure 3. The IR spectra of EO (Figures 3(b) and 3(c)) showed similar properties of functional groups as compared to $\mathrm{PKO}$ (Figure 3(a)). The O-H stretching was observed at $3411 \mathrm{~cm}^{-1}$. The peak of $\mathrm{C}=\mathrm{O}$ was observed at $1711 \mathrm{~cm}^{-1}$ and that of $\mathrm{C}-\mathrm{O}$ at $1115 \mathrm{~cm}^{-1}$ which indicated the presence of ester. It was envisaged that the EO contains heavy oil as the IR showed similarity of functional groups present in $\mathrm{PKO}$ and EO. This is because esterification via reactive distillation could produce two types of modified bio-oil, which are light and heavy oil. The IR spectra of the light oil consisted of various ester compounds while the heavy oil was similar with the original bio-oil [14]. It was believed that the EO obtained in this study might consist of a mixture of light oil (volatile component) and heavy oil (nonvolatile component). No separation was performed on the volatile and nonvolatile component during esterification, which therefore resulted in similar IR spectra of PKO and EO.

3.2. Physical Characteristics of Esterified Bio-Oil (EO). Physical characteristics of EO are summarised in Table 3. EO4 was characterized for the physical properties due to no carboxylic acid observed and less amount of ketones and aldehyde attributed to less oxygenated compound in the esterified oil. All EO gave a pleasant smell after esterification as compared to acrid smoky odour in PKO. The pleasant smell was due to the ethyl esters compounds which generally have a fruity essence [15]. 


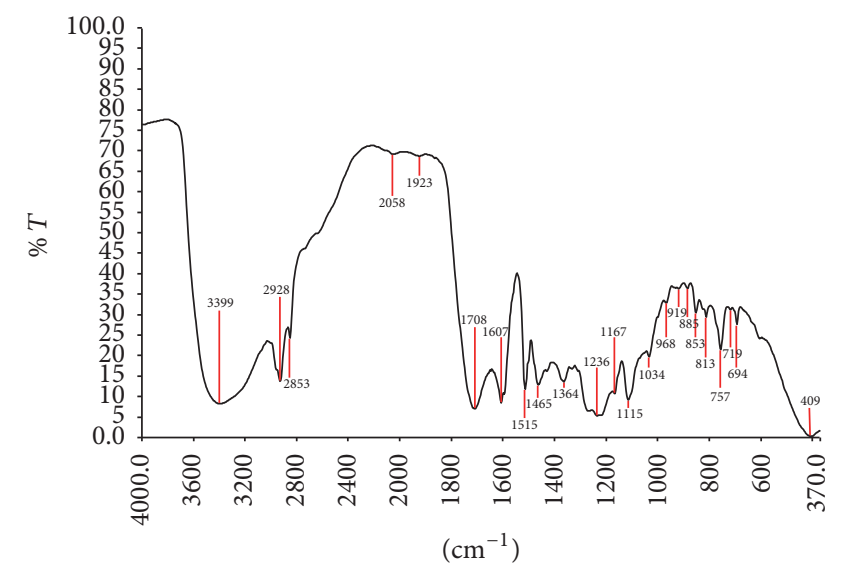

(a)

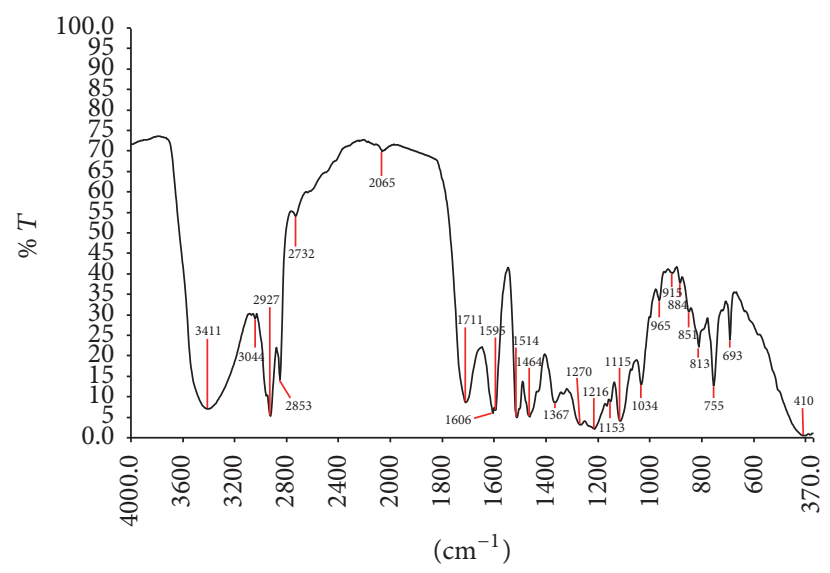

(b)

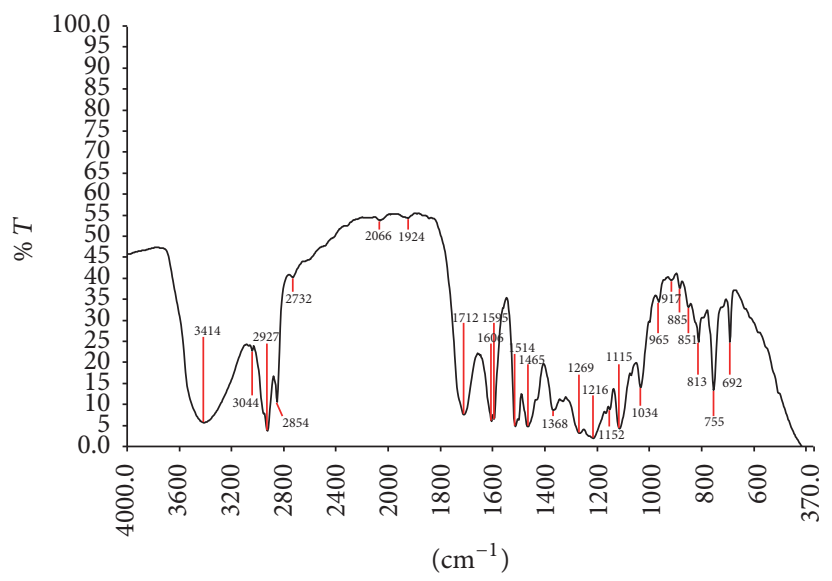

(c)

Figure 3: IR spectra of PKO and EO; (a) PKO and (b) EO concentrated at $35^{\circ} \mathrm{C}$; and (c) EO concentrated at $78^{\circ} \mathrm{C}$.

The $\mathrm{pH}$ value of $\mathrm{EO}$ was assuaged from 3.37 to 5.09 and 5.12, which represent the conversion of carboxylic acids into neutral ester. This result was in agreement with the $\mathrm{pH}$ value of heavy oil reported in [14]. The $\mathrm{pH}$ value of $\mathrm{EO}$ was slightly lower than the commercial diesel. The density of EO was reduced from $1.07 \mathrm{~g} / \mathrm{cm}^{3}$ to $0.94 \mathrm{~g} / \mathrm{cm}^{3}$ and $0.95 \mathrm{~g} / \mathrm{cm}^{3}$ which are comparable to other reported studies on catalytic esterification $[14,16]$.

The calorific value of $\mathrm{EO}$ was increased to $27 \%$ to perform heating value of $34.78 \mathrm{MJ} / \mathrm{kg}$. The EO which was concentrated at $78^{\circ} \mathrm{C}$ gave a higher calorific value up to $41.52 \mathrm{MJ} / \mathrm{kg}$. This result might be attributed from the elimination of unreacted ethanol in the EO. The incorporation with ethanol could reduce the extent of carbon in the mixture thus lowering the heating value of $\mathrm{EO}$ concentrated at $35^{\circ} \mathrm{C}$ as compared to $\mathrm{EO}$ concentrated at $78^{\circ} \mathrm{C}$ [15]. Esterification and dehydration of EO using molecular sieve assisted in decreasing the water content of bio-oil [16], thus resulting in higher calorific value of EO compared to PKO. The lower calorific value of EO compared to commercial diesel might be due to the existence of oxygenated compounds in the EO. The result is in agreement with the GC-MS analysis where high percentage of phenol and its derivatives was observed in the EO. In this study, the conversion of carboxylic into ester has primarily improved the $\mathrm{pH}$ of the bio-oil. Low $\mathrm{pH}$ of bio-oil indicates it is less corrosive when applied in the internal combustion engine [20]. Besides lowered acidity, the addition of polar solvents in the esterification like ethanol gives an immediate effect by lowering the density and increasing the calorific value of the bio-oil [21]. Thus, the esterified bio-oil could possibly be used in the more robust combustion engines, such as slow and medium-speed diesel engines, which require lower acidity and water content than those found in the raw bio-oil [20]. However, there are more specifications tests needed before the EO can be deemed suitable for real engine applications.

\section{Conclusion}

Esterification of PKO was performed with ethanol and sulphuric acid (as catalyst) to improve the $\mathrm{pH}$ and calorific value of the microwave bio-oil. The analysis of composition proved that the desirable ester compounds were found higher in the EO compared to pyrolytic oil before esterification, indicating the successful esterification of PKO. The undesirable compounds such as aldehyde, ketones, and carboxylic acid 
were reduced in the EO. The esterification procedure has improved the smell of the oil to an acceptable smell. The $\mathrm{pH}$ value of PKO was raised from 3.37 to 5.09 and 5.12 while the density of PKO was reduced from 1.07 to 0.94 and $0.95 \mathrm{~g} / \mathrm{cm}^{3}$. Esterification has also improved the calorific value of the PKO from 27.19 to 34.78 and $41.52 \mathrm{MJ} / \mathrm{kg}$. Conclusively, the EO has comparatively better properties in terms of its smell, $\mathrm{pH}$, calorific value, and absence of environmentally undesirable compounds. However, future works should include ASTM 6751 specifications tests for biodiesel to evaluate the bio-oil's suitability for commercial use.

\section{Conflicts of Interest}

The authors declare that they have no conflicts of interest.

\section{Acknowledgments}

The authors wish to express their appreciation to the Ministry of Higher Education Malaysia and Universiti Malaysia Sarawak for the financial support (Grant no. PRGS/TK04(01)/1268/2015(02)).

\section{References}

[1] S. Yaman, "Pyrolysis of biomass to produce fuels and chemical feedstocks," Energy Conversion and Management, vol. 45, no. 5, pp. 651-671, 2004.

[2] A. A. Salema and F. N. Ani, "Microwave induced pyrolysis of oil palm biomass," Bioresource Technology, vol. 102, no. 3, pp. 33883395, 2011.

[3] Y. F. Huang, W. H. Kuan, S. L. Lo, and C. F. Lin, “Total recovery of resources and energy from rice straw using microwaveinduced pyrolysis," Bioresource Technology, vol. 99, no. 17, pp. 8252-8258, 2008.

[4] P. Monsef-Mirzai, M. Ravindran, W. R. McWhinnie, and P. Burchill, "Rapid microwave pyrolysis of coal. Methodology and examination of the residual and volatile phases," Fuel, vol. 74, no. 1, pp. 20-27, 1995.

[5] K. El Harfi, A. Mokhlisse, M. B. Chanâa, and A. Outzourhit, "Pyrolysis of the Moroccan (Tarfaya) oil shales under microwave irradiation," Fuel, vol. 79, no. 7, pp. 733-742, 2000.

[6] C. Ludlow-Palafox and H. A. Chase, "Microwave-induced pyrolysis of plastic wastes," Industrial and Engineering Chemistry Research, vol. 40, no. 22, pp. 4749-4756, 2001.

[7] A. Domínguez, J. A. Menéndez, M. Inguanzo, and J. J. Pís, "Production of bio-fuels by high temperature pyrolysis of sewage sludge using conventional and microwave heating," Bioresource Technology, vol. 97, no. 10, pp. 1185-1193, 2006.

[8] J. A. Menéndez, A. Domínguez, M. Inguanzo, and J. J. Pis, "Microwave pyrolysis of sewage sludge: analysis of the gas fraction," Journal of Analytical and Applied Pyrolysis, vol. 71, no. 2, pp. 657-667, 2004.

[9] M. Miura, H. Kaga, A. Sakurai, T. Kakuchi, and K. Takahashi, "Rapid pyrolysis of wood block by microwave heating," Journal of Analytical and Applied Pyrolysis, vol. 71, no. 1, pp. 187-199, 2004.

[10] F. Yu, R. Ruan, and P. Steele, "Microwave pyrolysis of corn stover," Transactions of the ASABE, vol. 52, no. 5, pp. 1595-1601, 2009.
[11] A. Domínguez, J. A. Menéndez, Y. Fernández et al., "Conventional and microwave induced pyrolysis of coffee hulls for the production of a hydrogen rich fuel gas," Journal of Analytical and Applied Pyrolysis, vol. 79, no. 1-2, pp. 128-135, 2007.

[12] X.-H. Wang, H.-P. Chen, X.-J. Ding, H.-P. Yang, S.-H. Zhang, and Y.-Q. Shen, "Properties of gas and char from microwave pyrolysis of pine sawdust," BioResources, vol. 4, no. 3, pp. 946959, 2009.

[13] T. J. Appleton, R. I. Colder, S. W. Kingman, I. S. Lowndes, and A. G. Read, "Microwave technology for energy-efficient processing of waste," Applied Energy, vol. 81, no. 1, pp. 85-113, 2005.

[14] X. Junming, J. Jianchun, S. Yunjuan, and L. Yanju, "Bio-oil upgrading by means of ethyl ester production in reactive distillation to remove water and to improve storage and fuel characteristics," Biomass and Bioenergy, vol. 32, no. 11, pp. 10561061, 2008.

[15] V. A. Doshi, H. B. Vuthaluru, and T. Bastow, "Investigations into the control of odour and viscosity of biomass oil derived from pyrolysis of sewage sludge," Fuel Processing Technology, vol. 86, no. 8, pp. 885-897, 2005.

[16] Q. Zhang, J. Chang, T. Wang, and Y. Xu, "Upgrading bio-oil over different solid catalysts," Energy and Fuels, vol. 20, no. 6, pp. 2717-2720, 2006.

[17] M. Garcia-Perez, A. Chaala, H. Pakdel, D. Kretschmer, and C. Roy, "Characterization of bio-oils in chemical families," Biomass and Bioenergy, vol. 31, no. 4, pp. 222-242, 2007.

[18] Z.-G. Guo, S.-R. Wang, and Y.-Y. Zhu, "Catalytic esterification of model compounds of biomass pyrolysis oil," in Proceedings of the International Conference on Energy and Environment Technology (ICEET '09), pp. 545-547, Guilin, China, October 2009.

[19] Y. Liu, E. Lotero, and J. G. Goodwin Jr., "Effect of water on sulfuric acid catalyzed esterification," Journal of Molecular Catalysis A: Chemical, vol. 245, no. 1-2, pp. 132-140, 2006.

[20] T. Sundqvist, A. Oasmaa, and A. Koskinen, "Upgrading fast pyrolysis bio-oil quality by esterification and azeotropic water removal," Energy and Fuels, vol. 29, no. 4, pp. 2527-2534, 2015.

[21] S. Xiu and A. Shahbazi, "Bio-oil production and upgrading research: a review," Renewable and Sustainable Energy Reviews, vol. 16, no. 7, pp. 4406-4414, 2012. 

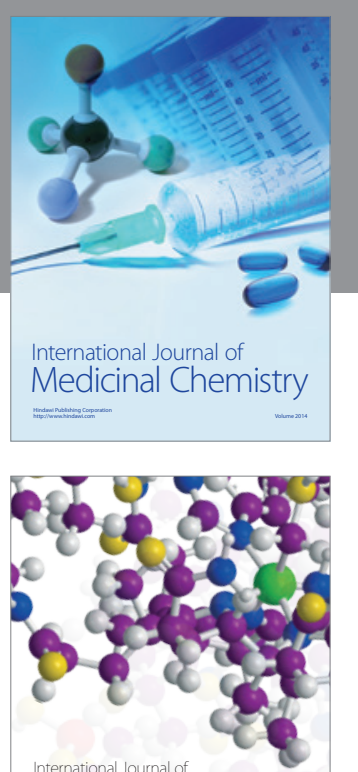

Carbohydrate Chemistry

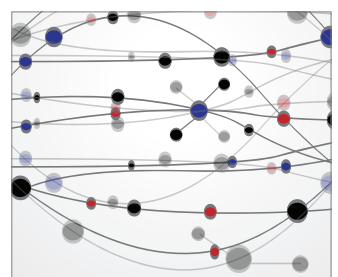

The Scientific World Journal
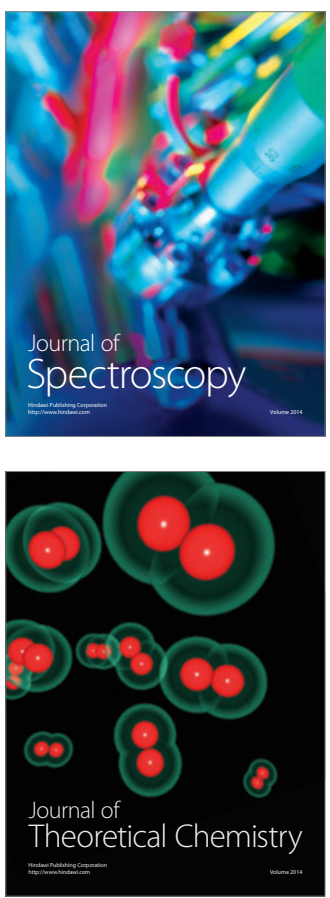
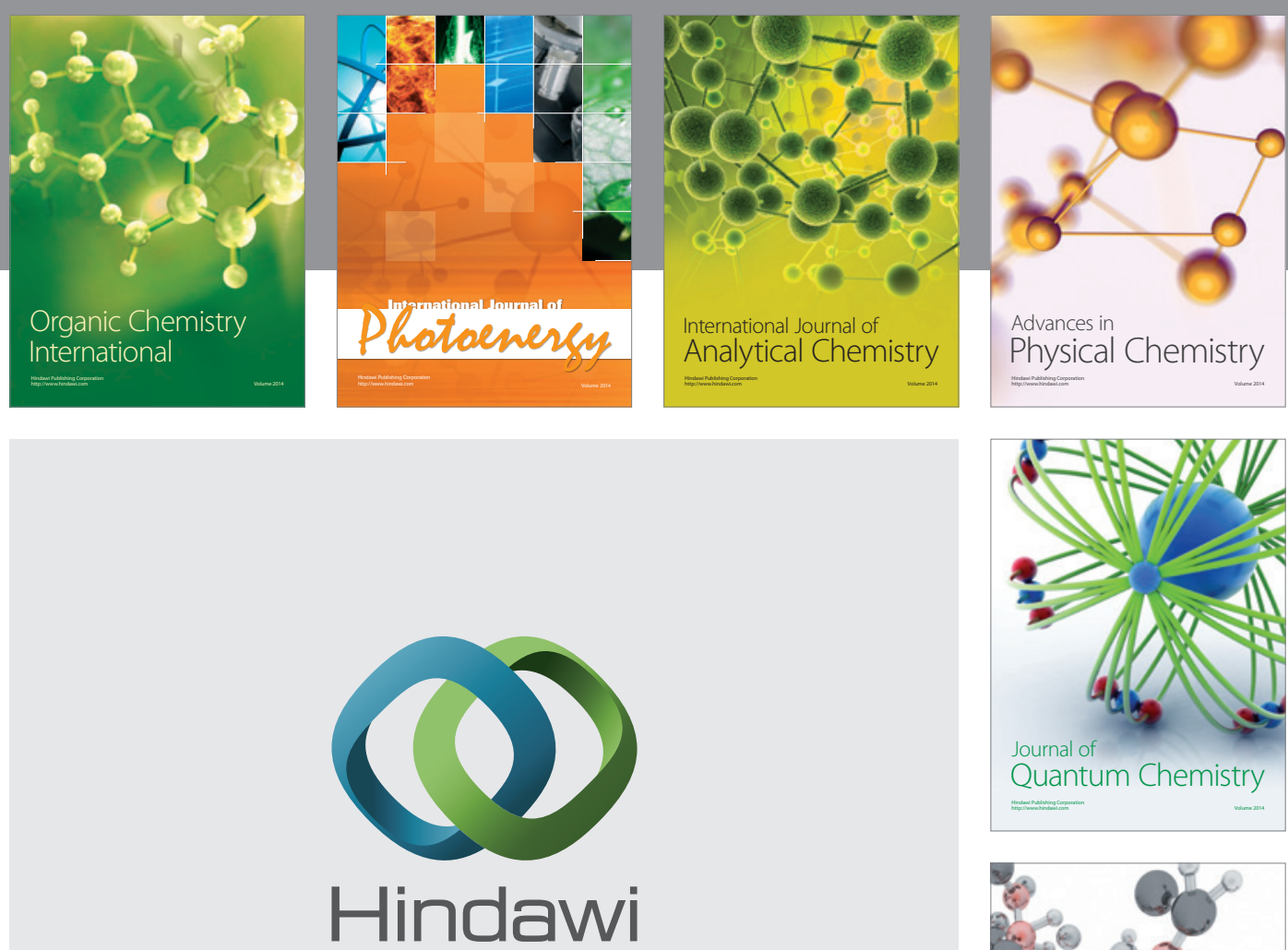

Submit your manuscripts at

https://www.hindawi.com

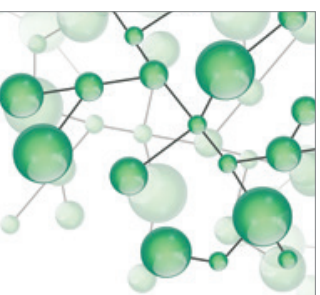

International Journal of

Inorganic Chemistry
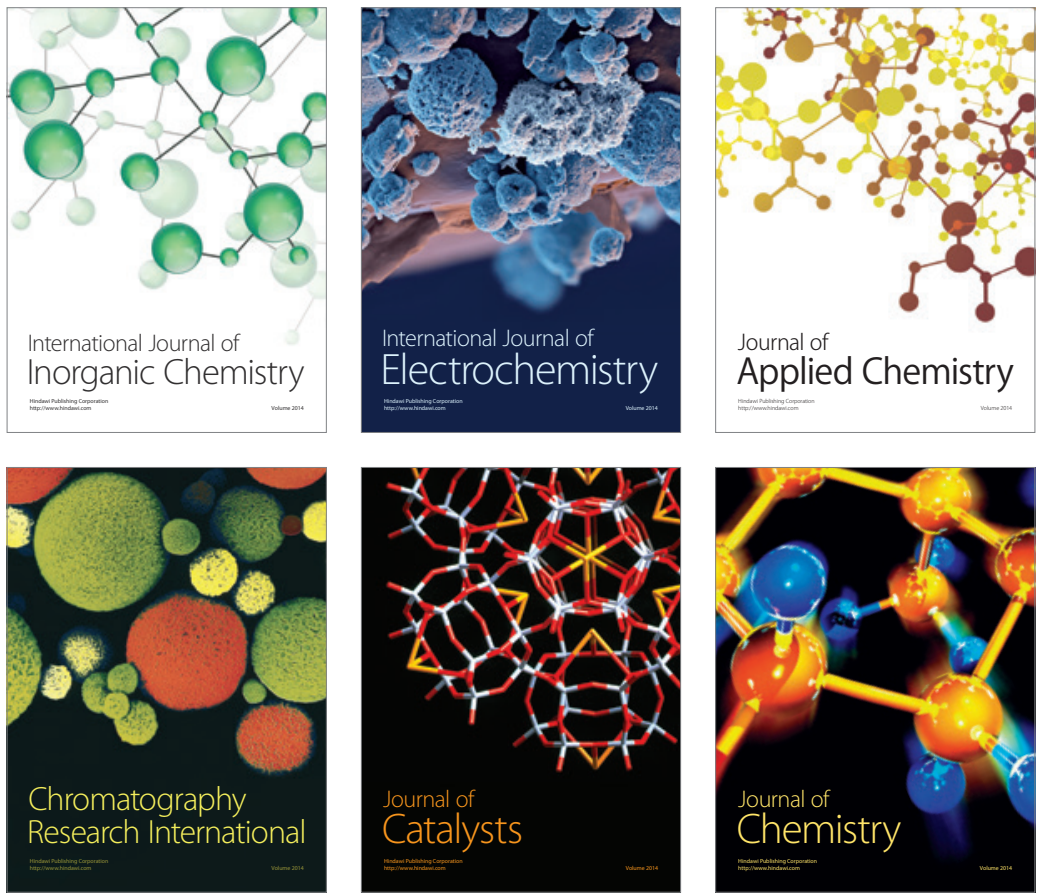

Journal of

Applied Chemistry
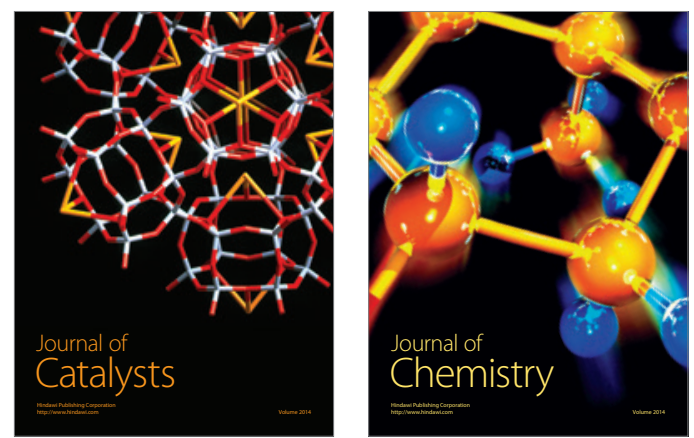
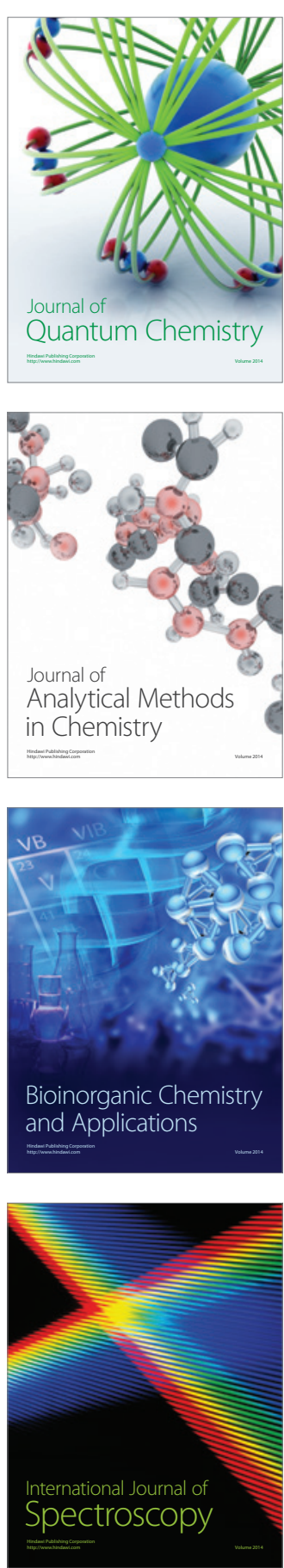